\title{
ANALISIS DAYA TAMPUNG BEBAN PENCEMAR BOD, COD, DAN TSS DI SUNGAI WIDURI DENGAN MENGGUNAKAN SOFTWARE QUAL2KW
}

\author{
Yevan Okta Wifarulah ${ }^{1}$, Nelly Marlina ${ }^{1)}$ \\ ${ }^{1)}$ Program Studi Teknik Lingkungan, Fakultas Teknik Sipil dan Perencanaan, Universitas Islam Indonesia, \\ Yogyakarta \\ Email : nelly.marlina@uii.ac.id
}

\begin{abstract}
Abstrak
Sungai Widuri berhulu di wilayah Kabupaten Sleman, mengalir melalui wilayah tepi Kota Yogyakarta dan masuk Kabupaten Bantul. Sungai Widuri banyak dimanfaatkan sebagai sarana mencuci, mandi, dan toilet. Selain itu, Sungai Widuri juga membawa air limbah yang berasal dari pertanian, peternakan, perikanan, dan kegiatan industri. Penelitian bertujuan menganalisis daya tampung beban pencemar yang dapat diterima Sungai Widuri dengan menggunakan software pemodelan air QUAL2Kw. Software pemodelan QUAL2Kw merupakan salah satu software yang direkomendasikan untuk menghitung daya tampung beban pencemar dari Peraturan Menteri Negara Lingkungan Hidup nomor 1 tahun 2010 tentang Tata Laksana Pengendalian Pencemaran Air. Parameter Biochemical Oxygen Demand (BOD), Chemical Oxygen Demand (COD), dan Total Suspended Solid (TSS) digunakan sebagai parameter pencemar sungai. Berdasarkan penelitian, didapatkan nilai daya tampung parameter BOD adalah: segmen 1 sebesar 2617,919 kg/hari, segmen 2 sebesar 152,918 kg/hari, segmen 3 sebesar 0,040 kg/hari, segmen 4 sebesar 199,579 kg/hari, parameter COD adalah: segmen 1 sebesar 21815,948 kg/hari, segmen 2 sebesar 1274,314 kg/hari, segmen 3 sebesar 0,318 kg/hari, segmen 4 sebesar 1663,194 kg/hari, dan parameter TSS adalah: segmen 1 sebesar 43631,896 kg/hari, segmen 2 sebesar 2548,627 kg/hari, segmen 3 sebesar 0,635 kg/hari, segmen 4 sebesar 3326,387 $\mathrm{kg} / \mathrm{hari}$. Secara keseluruhan nilai daya tampung pada semua parameter dan setiap segmen masih bernilai positif (+) yang menyatakan nilai daya tampung beban pencemar yang dapat diterima oleh Sungai Widuri.
\end{abstract}

Kata Kunci : Daya Tampung, Parameter, Qual2Kw, Sungai Widuri

\begin{abstract}
The headwater of Widuri river in Sleman regency, flowing throught side area in Yogyakarta City, and the downstream in Bantul regency. The Widuri river have a lot use as domestic activity. Other that, Widuri river also receive wastewater from agriculture, animal husbandry, fishery, and industrial activity. The purpose of this research is analysis of water capacity from Widuri river using Qual2Kw software. The Qual2Kw software one of many methods that recomended from Peraturan Menteri Negara Lingkungan Hidup no. 1 tahun 2010 tentang Tata Laksana Pengendalian Pencemaran Air. Biolchemical Oxygen Demand (BOD), Chemical Oxygen Demand (COD), and Total Suspended Solid (TSS) as the pollutan parameter. The result of water capacity in river, the BOD parameter has $2617,919 \mathrm{~kg} /$ day in segment 1, 152,918 kg/day in segment 2, 0,040 in segment 3, and 199,579 kg/day in segment 4. The COD parameter has 21815,948 kg/day in segment 1, 1274,314 kg/day in segment 2, 0,318 kg/day in segment 3, and 1663,194 kg/day in segment 4. The TSS parameter has 43631,896 kg/day in segment 1, 2548,627 kg/day in segment 2, 0,635 kg/day in segment 3, and 3326,387 in segment 4 . So the water capacity value for all parameter in every segmen has positive value that mean can receive from Widuri river.
\end{abstract}

Key Word : Parameter, Qual2Kw, Water Capacity, Widuri River

Dikirim/submitted: 7 Desember 2020

Diterima/accepted: 8 Januari 2021 


\section{PENDAhUluAN}

Peningkatan jumlah penduduk dan perkembangan suatu kota berakibat pada pola perubahan konsumsi masyarakat yang cukup tinggi dari tahun ke tahun, dengan luas lahan yang tetap akan mengakibatkan tekanan terhadap lingkungan semakin berat. Aktivitas manusia dalam memenuhi kebutuhan hidupnya yang berasal dari pertanian, industri dan kegiatan rumah tangga akan menghasilkan limbah yang memberi sumbangan pada penurunan kualitas air sungai (Mahyudin, 2015). Penurunan kualitas air terjadi sebagai akibat pembuangan limbah yang tidak terkendali dari aktifitas disepanjang sungai sehingga tidak sesuai dengan daya dukung sungai (Prihartanto, 2007).

Sungai Widuri dengan panjang total 26,9 km adalah sungai yang selalu mengalir sepanjang tahun. Sungai ini berhulu di wilayah Kabupaten Sleman, mengalir melalui wilayah tepi Kota Yogyakarta dan masuk Kabupaten Bantul. Muara sungai masuk ke Sungai Bedog dan akhirnya masuk ke Sungai Progo. Sungai Widuri berhulu di Kecamatan Pakem, melintasi Kecamatan Ngaglik, Sleman, Mlati, dan Gamping, selanjutnya memasuki Kecamatan Kasihan. Sebagai gambaran, kampung-kampung di pingggiran Kota Yogyakarta yang terlewati oleh sungai ini antara lain Cungkuk, Kadipiro, Ketanggungan, Bugisan, Sonosewu, Nitiprayan, dan Jeblog. Kampung-kampung di perkotaan tersebut sudah sangat padat penduduk dan bangunan-bangunannya, masuk dalam wilayah Kabupaten Bantul dan Kota Yogyakarta. Sungai Widuri banyak di manfaatkan sebagai sarana mencuci, mandi, dan toilet. Selain itu, Sungai Widuri juga membawa air limbah yang berasal dari pertanian, peternakan, perikanan, dan kegiatan industri. Oleh karena itu, pada penelitian kali ini menggunakan parameter Biochemical Oxygen Demand (BOD), Chemical Oxygen Demand (COD), dan Total Suspended Solid (TSS) sebagai parameter pencemar sungai karena parameter tersebut merupakan yang paling dominan ada dari kegiatan-kegiatan tersebut sehingga ada indikasi sungai Widuri dapat tercemar dari kegiatan-kegiatan yang ada di sekitar.

Air sungai biasanya akan meresap dan menjadi sumber air sumur warga di sekitar sungai serta menjadi estetika lingkungan sekitar sungai, apabila tercemar kemungkinan akan mengurangi kualitas air sumur warga serta estetika lingkungan sungai tersebut. Penelitian tentang daya tampung Sungai Widuri belum pernah dilakukan, sehingga perlu dilakukan penelitian daya tampungnya agar mengetahui seberapa besar Sungai Widuri dapat menampung beban pencemaran yang diterimanya. Penelitian yang dilakukan adalah menganalisa daya tampung Sungai Widuri dengan menggunakan software pemodelan QUAL2Kw, sehingga harapannya dapat mengetahui apakah Sungai Widuri telah tercemar dan mengetahui batas Sungai Widuri untuk menampung beban pencemar. Software pemodelan QUAL2Kw dipilih karena telah banyak digunakan dalam pemodelan kualitas air dan telah berpengaruh baik dibeberapa tahun terakhir serta dapat melakukan simulasi terhadap objek yang dimodelkan. Selain itu, software QUAL2Kw direkomendasikan untuk menghitung nilai daya tampung oleh Peraturan Menteri Negara Lingkungan Hidup Nomor 1 Tahun 
2010 tentang Tata Laksana Pengendalian Pencemaran Air. Penentuan daya tampung beban pencemaran akan diperoleh Batasan limbah yang diperbolehkan masuk ke dalam sungai agar sungai mampu memperbaiki kondisi kualitas airnya secara alami (self purification) serta diperoleh hasil penurunan beban pencemaran sungai untuk setiap parameter (Irsanda, 2014).

Tujuan dari penelitian ini adalah melakukan analisis kualitas air Sungai Widuri dengan parameter BOD (Biochemical Oxygen Demand), COD (Chemical Oxygen Demand), dan TSS (Total Suspended Solid) dengan membandingkan baku mutu Peraturan Gubernur DIY no. 20 tahun 2008 dan melakukan analisis daya tampung beban pencemar BOD (Biochemical Oxygen Demand), COD (Chemical Oxygen Demand), dan TSS (Total Suspended Solid) dengan menggunakan software pemodelan QUAL2KW.

\section{METODE PENELITIAN}

Ruang lingkup dari penelitian hanya mencakup parameter BOD, COD dan TSS dengan hasil penelitian berupa nilai daya tampung beban pencemar yang dapat diterima Sungai Widuri, serta panjang Sungai Widuri yang diteliti sepanjang 9,456 km dengan 5 stream point dan 4 segmen. Penelitian dimulai dari Kecamatan Gamping tepatnya di Desa Trihanggo (S 0744'56.8", E $\left.110^{\circ} 22^{\prime} 08.0^{\prime \prime}\right)$ hingga jembatan widuri di jalan ringroad selatan (S 0749'31.9", E 110²0'18.4"). Pengumpulan data dalam penelitian ini adalah berupa data primer dan data sekunder. Data primer yang diambil meliputi kualitas air sungai dan kondisi hidrolik sungai. Setelah dilakukan pembagian segmen (reach), data yang telah didapatkan kemudian dimasukkan ke dalam program QUAL2Kw untuk membentuk model. Sedangkan data sekunder yang dikumpulkan meliputi peta dan data klimatologi yang terdiri dari kecepatan angin, temperatur udara, tutupan awan, radiasi matahari, tutupan awan, temperatur titik embun.

Setelah data dimasukkan dan QUAL2Kw dijalankan, untuk dapat membentuk model diperlukan proses kalibrasi. Kalibrasi dilakukan dengan cara trial and error. Trial and error dilakukan dengan menambahkan asumsi beberapa effluent yang masuk ke badan air yang dianggap tidak terpantau pada saat tahap sampling. Selain itu, trial and error juga dilakukan dengan memainkan angka reaeration, Oxidation rate $\mathrm{CBODf}$, dan decay rate pada generic yang terdapat pada reach rate worksheet hingga model mendekati tren yang dibentuk oleh data grafik. Setelah proses kalibrasi maka dilakukan proses validasi, proses ini bertujuan untuk mengetahui apakah model dapat digunakan untuk simulasi nantinya, validasi dilakukan dengan metode Root Mean Square Percent Error (RMSPE) yang digunakan untuk mengkuantifikasi besar dan sifat error yang terjadi. 
RMSPE mengukur rata-rata prosentase perbedaan antara data aktual dan hasil simulasi sesuai Persamaan 1.

$$
R M S P E=\sqrt{\frac{1}{n}\left[\sum_{n=1}^{n}\left(\frac{S t-A t}{A t}\right)^{2}\right]} \times 100 \%
$$

Keterangan :

$$
\begin{array}{ll}
\text { RMSPE } & \text { : Root Mean Square Percent Error } \\
\text { St } & \text { : Nilai simulasi pada waktu } \mathrm{t} \\
\text { At } & \text { : Nilai aktual pada waktu } \mathrm{t} \\
\mathrm{n} & \text { : Jumlah pengamatan }(\mathrm{t}=1,2, \ldots, \mathrm{n})
\end{array}
$$

Model yang telah tervalidasi dapat digunakan untuk melakukan berbagai skenario simulasi terhadap kondisi sungai. Terdapat tiga skenario simulasi seperti yang ditunjukkan pada Tabel 1.

Tabel 1. Skenario Teknik Simulasi

\begin{tabular}{cccc}
\hline Skenario & Kondisi Air Hulu & Sumber Pencemar & Kondisi Air Sungai \\
\hline $\mathbf{1}$ & Eksisting & Eksisting & Model \\
\hline $\mathbf{2}$ & Eksisting & Kondisi Awal & Model \\
\hline $\mathbf{3}$ & Baku Mutu Kelas II & Trial and error & Baku Mutu Kelas II \\
\hline
\end{tabular}

Berdasarkan Tabel 1, skenario 1 merupakan kondisi air eksisting di lapangan baik pada hulu maupun pada effluent-nya, skenario 2 merupakan kondisi tanpa beban pencemar yang masuk, kecuali saluran drainase, dan skenario 3 merupakan kondisi pada hulu memenuhi baku mutu kelas II dengan kondisi effluent yang di trial and error hingga mendapatkan model yang mendekati baku mutu kelas II.

Penentukan daya tampung beban pencemar dilakukan dengan membandingkan skenario 3 dan skenario 2. Persamaan yang digunakan untuk menentukan daya tampung beban pencemar dapat dilihat pada Persamaan 2.

Daya Tampung = Beban pencemar maksimum (Skenario 3) - beban kondisi awal $($ Skenario 2)

Daya tampung beban pencemar didapat dengan melihat selisih beban cemaran maksimum dengan beban cemaran tanpa pencemar, apabila daya tampung bernilai positif (+) maka obyek masih mampu menampung beban pencemaran yang masuk, apaila daya tampung bernilai negatif (-), 
maka obyek sudah tidak mampu menerima beban pencemaran (Rusnugroho dan Masduqi, 2012). Tahapan dari penelitian dapat dilihat pada Gambar 1.

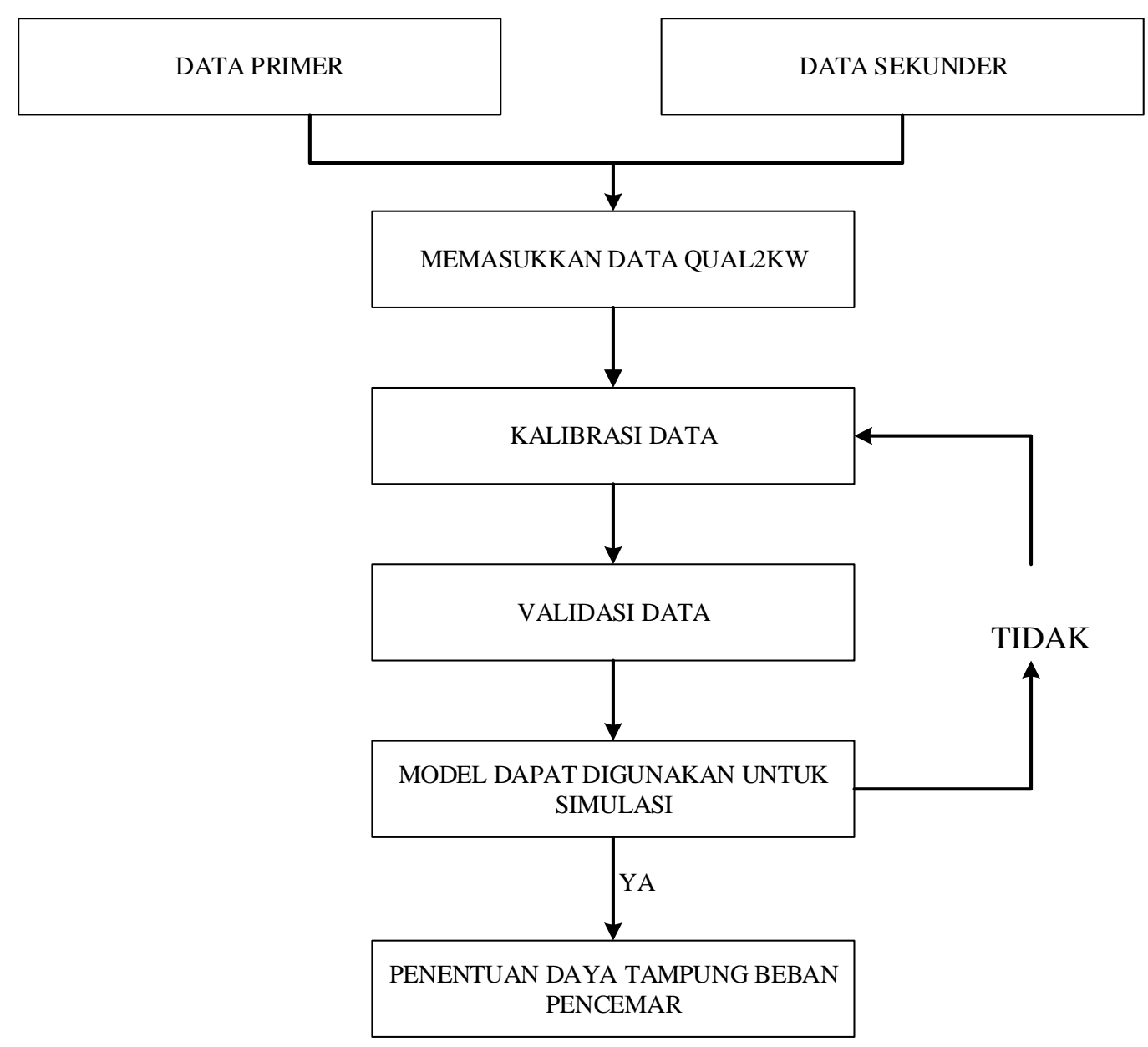

Gambar 1. Tahapan penentuan daya tampung beban pencemar

\section{HASIL DAN PEMBAHASAN}

\subsection{Kualitas Air Sungai}

Kualitas air dapat dinyatakan dengan parameter kualitas air. Parameter ini meliputi parameter fisik, kimia, dan mikrobiologis. Data kualitas air sungai berfungsi untuk mengetahui mutu dari air tersebut. pada penelitian kali ini, kualitas air berpedoman kepada Peraturan Gubernur Daerah Istimewa Yogyakarta nomor 20 tahun 2008 tentang Baku Mutu Air di DIY.

Total Suspended Solid (TSS) atau zat padat terlarut adalah padatan yang menyebabkan kekeruhan air, tidak terlarut, dan tidak dapat mengendap langsung. Padatan tersuspensi terdiri dari partikel- 
partikel yang ukuran maupun beratnya lebih kecil dari pada sedimen. Partikel yang dapat menurunkan intensitas cahaya yang tersuspensi dalam air umumnya terdiri dari fitoplankton, zooplankton, kotoran hewan, sisa tanaman dan hewan, kotoran manusia dan limbah industri (Yuliastuti, 2011). Hasil pengukuran TSS Sungai Widuri dapat dilihat pada Gambar 2.

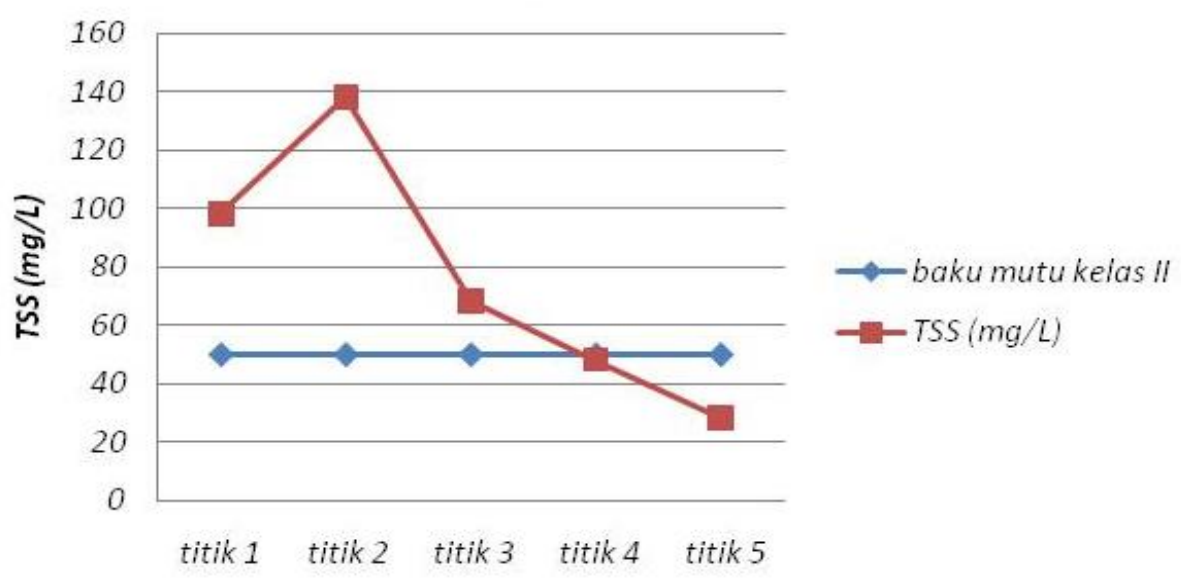

Gambar 2. Konsentrasi TSS

Berdasarkan Gambar 2 dapat dilihat bahwa konsentrasi TSS pada titik 1 ke titik 2 mengalami peningkatan, hal ini dikarenakan pada titik pantau 2 mengalami penigkatan laju aliran dari 0,33 $\mathrm{m} / \mathrm{s}$ menjadi $0,55 \mathrm{~m} / \mathrm{s}$. Selain itu, kondisi dasar saluran yang berpasir menyebabkan terbawanya partikel-partikel terlarut ke permukaan sungai dan menyebabkan air keruh. Namun, konsentrasi TSS dari titik pantau 3 hingga titik pantau 5 mengalami penurunan konsentrasi, hal ini dapat disebabkan oleh banyaknya batuan dan endapan sampah yang dapat menghambat atau menahan partikel terlarut, selain itu terdapat vegetasi seperti semak-semak dan akar pepohonan pada titik pantau 4 ke titik 5 yang juga dapat menahan partikel terlarut.

BOD merupakan jumlah oksigen yang dibutuhkan oleh mikroorganisme di dalam air untuk mendegradasi bahan organik yang ada di dalam air tersebut (Wardhana, 2004). Hasil pengukuran BOD Sungai Widuri dapat dilihat pada Gambar 3. Pada Gambar 3 menunjukkan konsentrasi BOD dari titik 1 hingga titik 3 mengalami penurunan karena terjadinya proses dekomposisi senyawasenyawa organik yang dipengaruhi oleh oksigen terlarut (Effendi, 2003). Namun dari titik 3 ke titik 4 mengalami peningkatan konsentrasi BOD sungai, fenomena ini mengindikasikan adanya pengaruh kegiatan disekitar Sungai Widuri seperti aktivitas kegiatan industri, pemukiman yang 
padat, dan sebagainya. Menurut (Yogafanny,2015) tingginya konsentrasi BOD yang terdapat dalam sungai memperlihatkan banyaknya bahan organic yang mampu didegradasi secara biologis hasil dari buangan air limbah domestik dan industri.

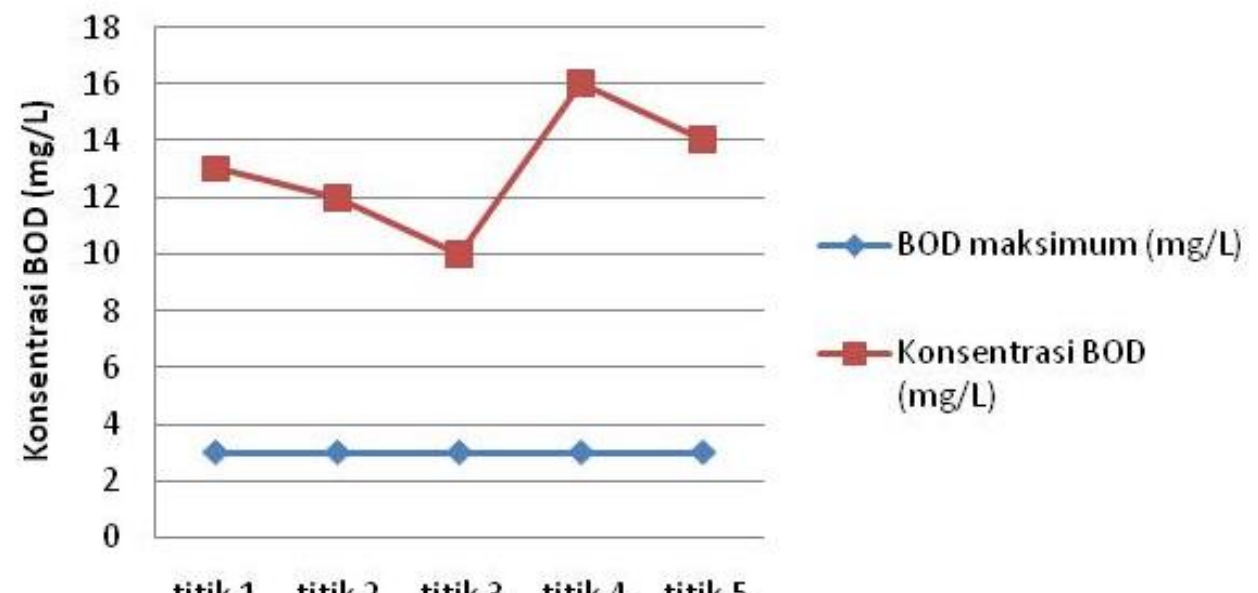

titik 1 titik 2 titik 3 titik 4 titik 5

Gambar 3. Konsentrasi BOD

COD atau kebutuhan oksigen kimia adalah jumlah okigen yang diperlukan agar bahan buangan yang ada dalam air dapat teroksidasi melalui reaksi kimia (Wardhana, 2004). Hasil pengukuran pada parameter COD ditunjukkan pada Gambar 4.

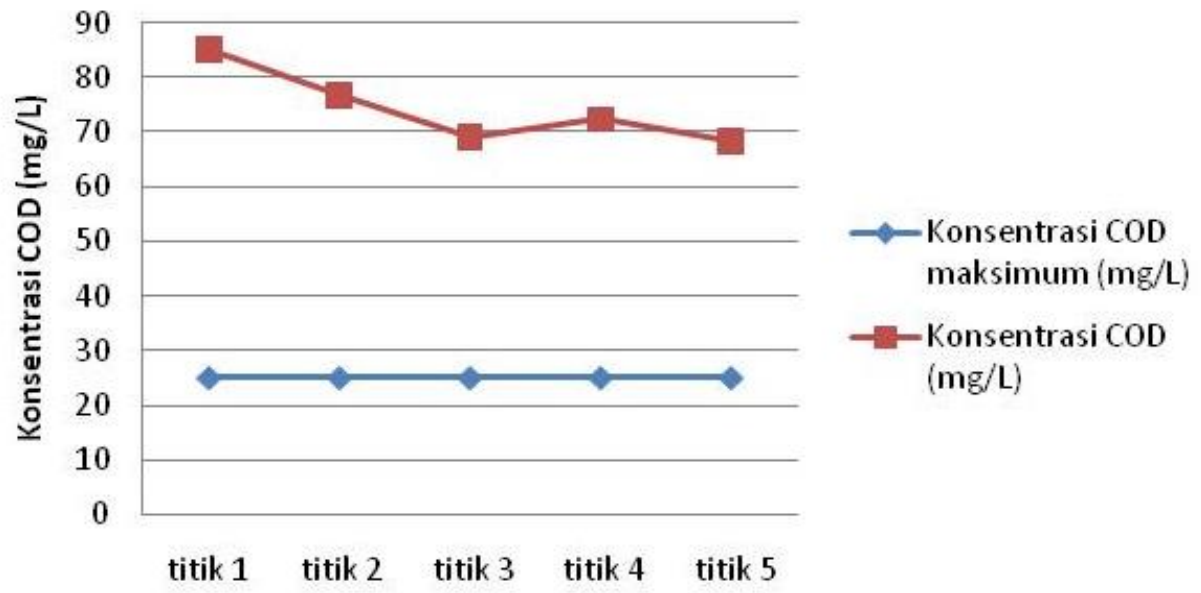

Gambar 4. Konsentrasi COD 
Dari Gambar 4 dapat dilihat bahwa konsentrasi COD Sungai Widuri relatif mengalami penurunan pada titik 1 sampai titik 3, hal ini dikarenakan bagian tersebut terjadi proses dekomposisi oleh mikroorganisme. Bagian ini disebut zona dekomposisi karena kaya akan bakteri dan mikroorganisme (Hendrasarie dan cahyarani, 2008). Pada titik 4 konsentrasi COD mengalami peningkatan dikarenakan masuk dalam zona biodegradasi sehingga konsentrasi COD meningkat. Selain itu, hal ini dapat dipengaruhi juga oleh aktivitas-aktivitas yang ada disekitar sungai pada titik tersebut.

\subsection{Pembentukan model QUAL2KW}

Kalibrasi adalah proses penentuan harga koefisien yang paling sesuai, sehingga perbandingan hasil model dengan data lapangan menunjukkan harga yang paling baik ditinjau secara statistik (Marlina, 2015). Kalibrasi data pada QUAL2Kw bertujuan dalam pembentukan model. Kalibrasi data hidrolik digunakan untuk pembentukan model data hidrolik berupa debit, kecepatan aliran dan kedalaman. Dari hasil data yang dimasukkan pada lembar kerja data hidrolik dan reach maka didapatkan hasil grafik debit, kecepatan aliran dan kedalaman. Selanjutnya kalibrasi kualitas air yang dilakukan dengan cara trial and error dengan menambahkan asumsi beberapa effluent yang masuk ke badan air pada lembar kerja point source yang dianggap tidak terpantau pada saat tahap sampling, dan trial and error pada lembar kerja reach rate.

Uji validitas merupakan tahap yang dilakukan setelah proses kalibrasi untuk memvalidasi parameter yang digunakan pada model. Perhitungan validasi dilakukan terhadap tiga parameter yaitu BOD, COD dan TSS. Berdasarkan hasil perhitungan validasi, diperoleh uji validitas data model adalah 36,4\% untuk TSS, 42,4\% untuk BOD, dan 7,2\% untuk COD. Hasil uji vaiditas terhadap ketiga parameter tersebut memiliki persentase dibawah 50\% atau dibawah 0,5. Menurut Deksissa (2004), uji validitas dengan nilai error dibawah 0,5 atau dibawah $50 \%$ dapat digunakan untuk menyatakan bahwa model dapat diterima. Hal ini menunjukkan bahwa model bisa digunakan untuk simulasi skenario daya tampung beban pencemar.

\subsection{Simulasi Skenario}

Simulasi model bertujuan agar mengetahui kondisi badan air sumber pencemar dari berbagai kondisi (Irsanda, 2014). Pada penelitian ini terdapat tiga simulasi skenario yang dilakukan yaitu skenario satu, dua dan tiga. Simulasi skenario satu merupakan skenario yang memberikan gambaran kondisi eksisting sungai, baik pada hulu maupun pada effluent yang masuk ke badan air. 
Pada skenario ini, dilakukan trial and error dengan menambah beban pencemar pada lembar kerja diffuse source hingga model mendekati data eksisting. Hasil simulasi skenario satu dapat dilihat pada Gambar 5, 6 dan 7 untuk paramter BOD, COD dan TSS secara berurutan. Dari hasil skenario satu dapat disimpulkan bahwa adanya peningkatan dan penurunan dari grafik model. Hal tersebut dipengaruhi adanya masukkan dari sumber pencemar dan pengambilan debit sungai.

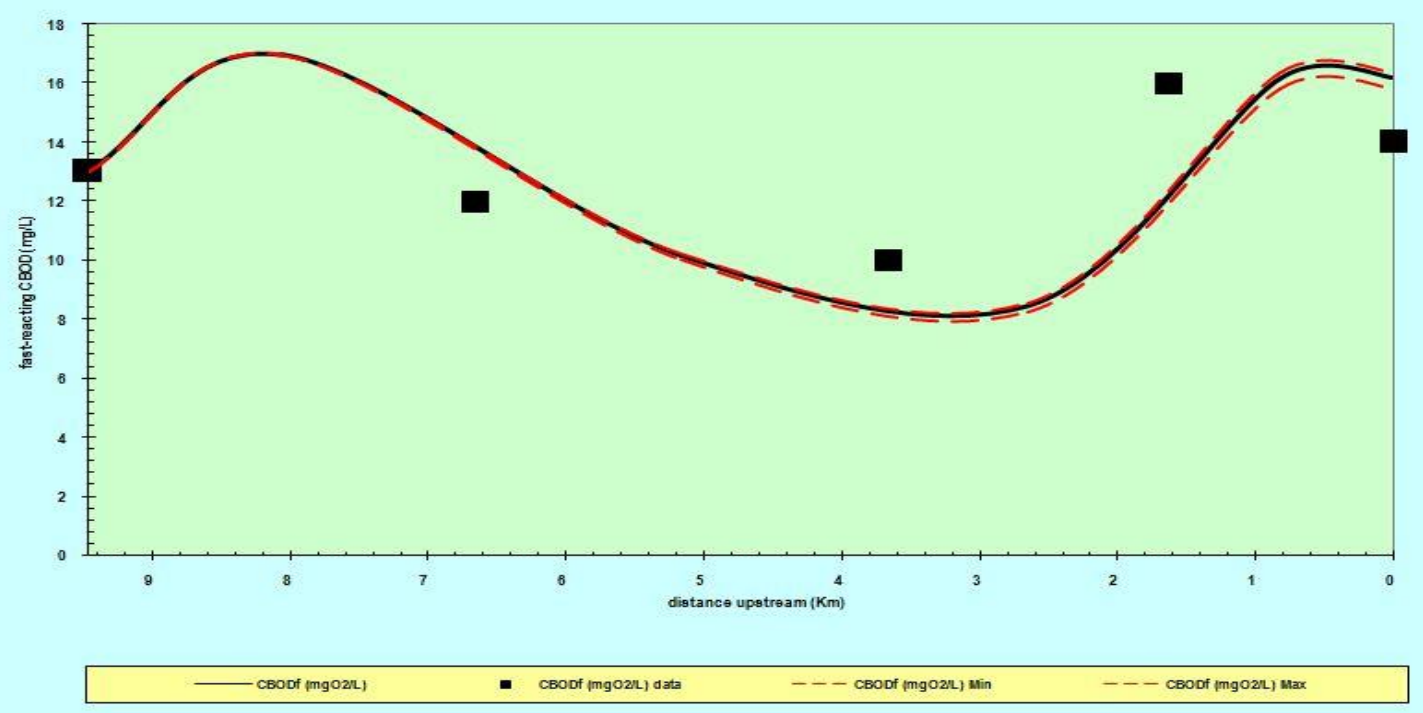

Gambar 5. Hasil model skenario satu parameter BOD

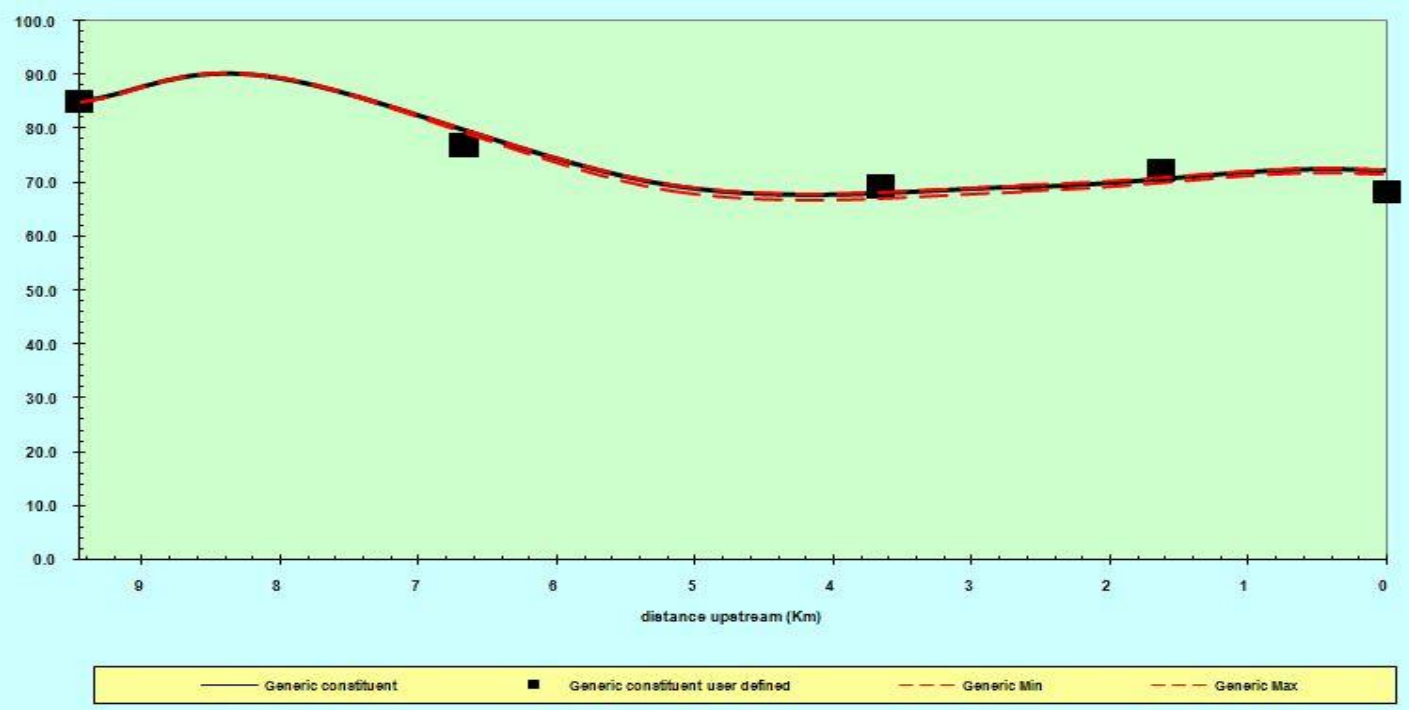

Gambar 6. Hasil model skenario satu parameter COD 


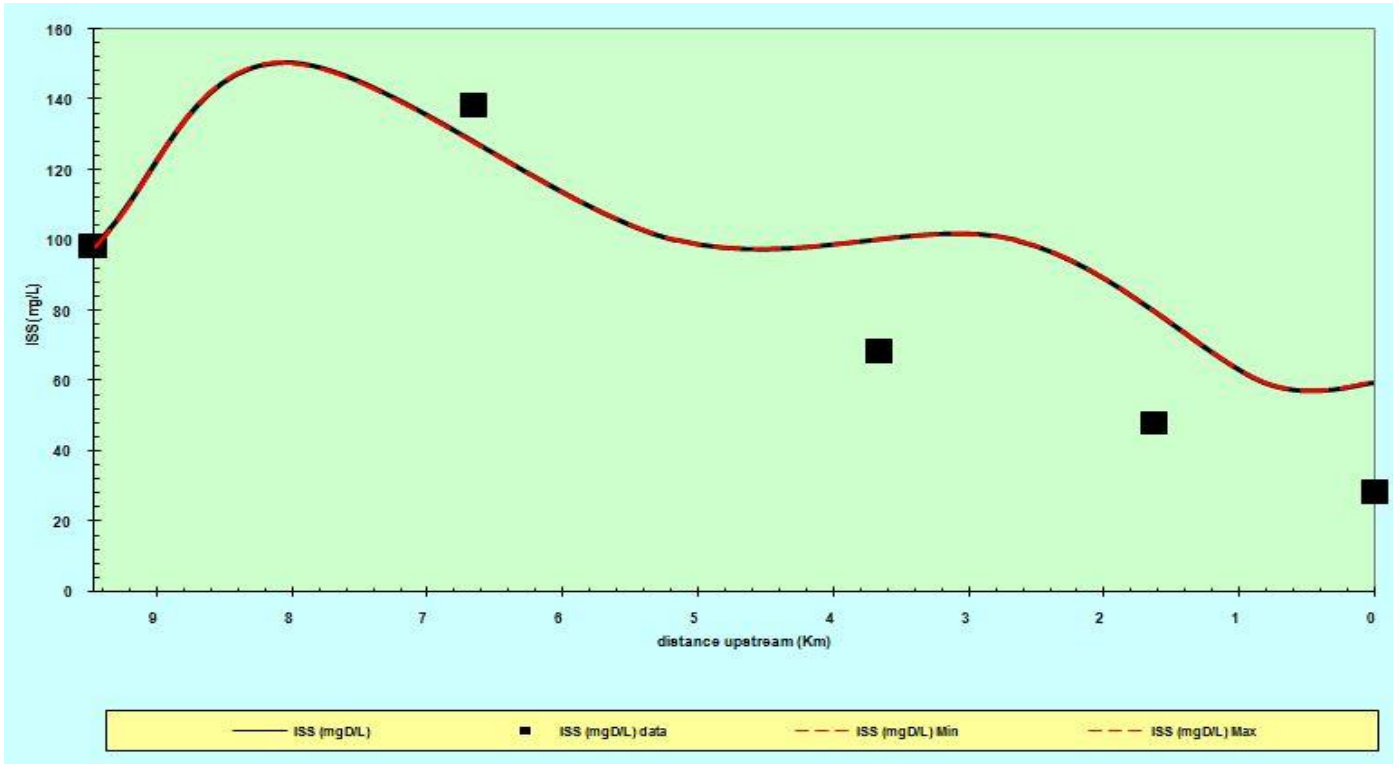

Gambar 7. Hasil model skenario satu parameter TSS

Simulasi model skenario dua merupakan skenario yang memberikan gambaran kondisi hulu sungai memenuhi baku mutu air kelas II dengan pedoman baku mutu air mengacu kepada Peraturan Gubernur DIY no. 20 tahun 2008 tentang Baku Mutu Air di DIY, dan mengabaikan sumber pencemar yang masuk kecuali untuk saluran drainase. Hasil dari simulasi model skenario dua ditunjukkan pada Gambar 8,9 dan 10 untuk paramater BOD, COD dan TSS secara berurutan.

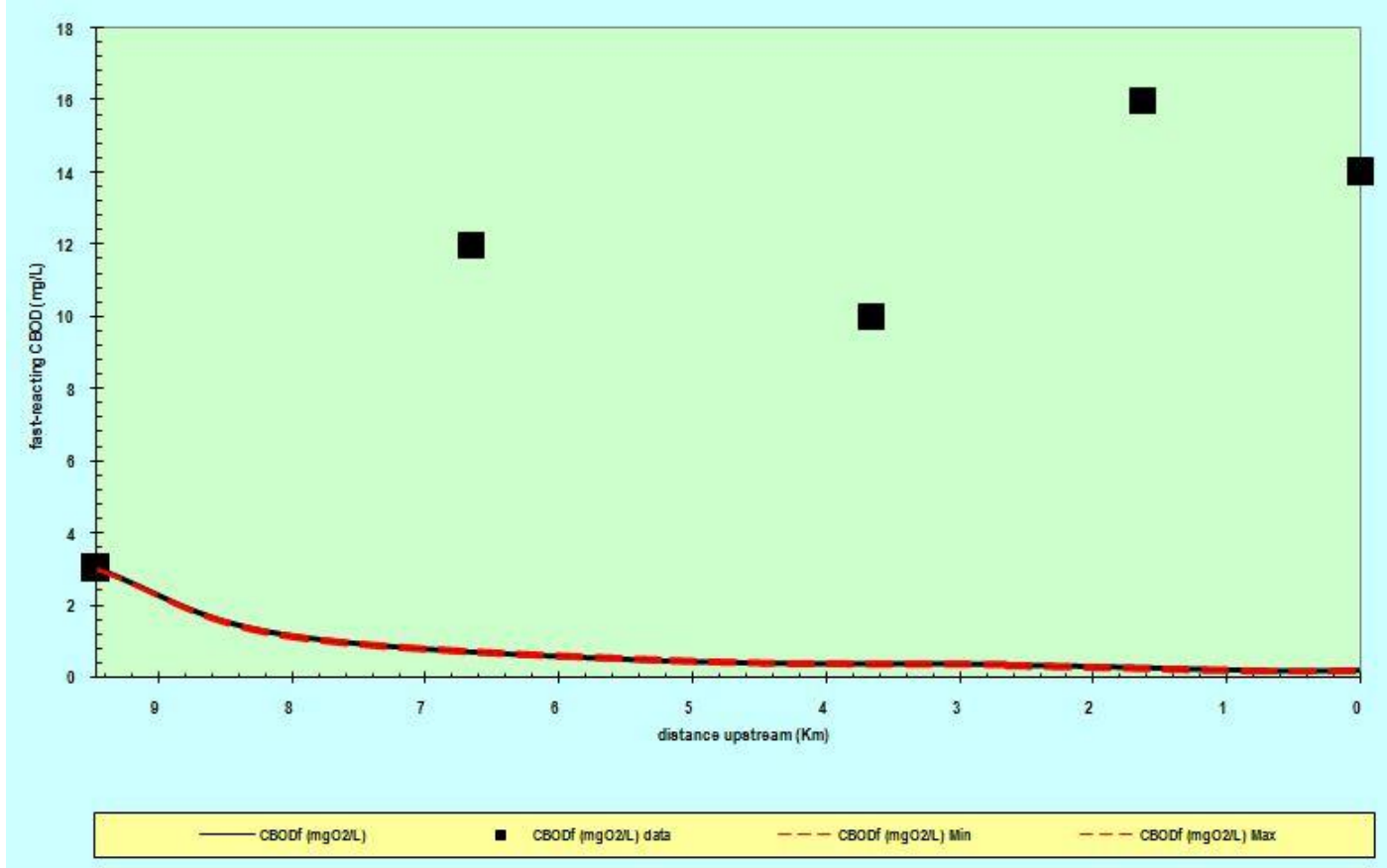

Gambar 8. Hasil model skenario dua parameter BOD 


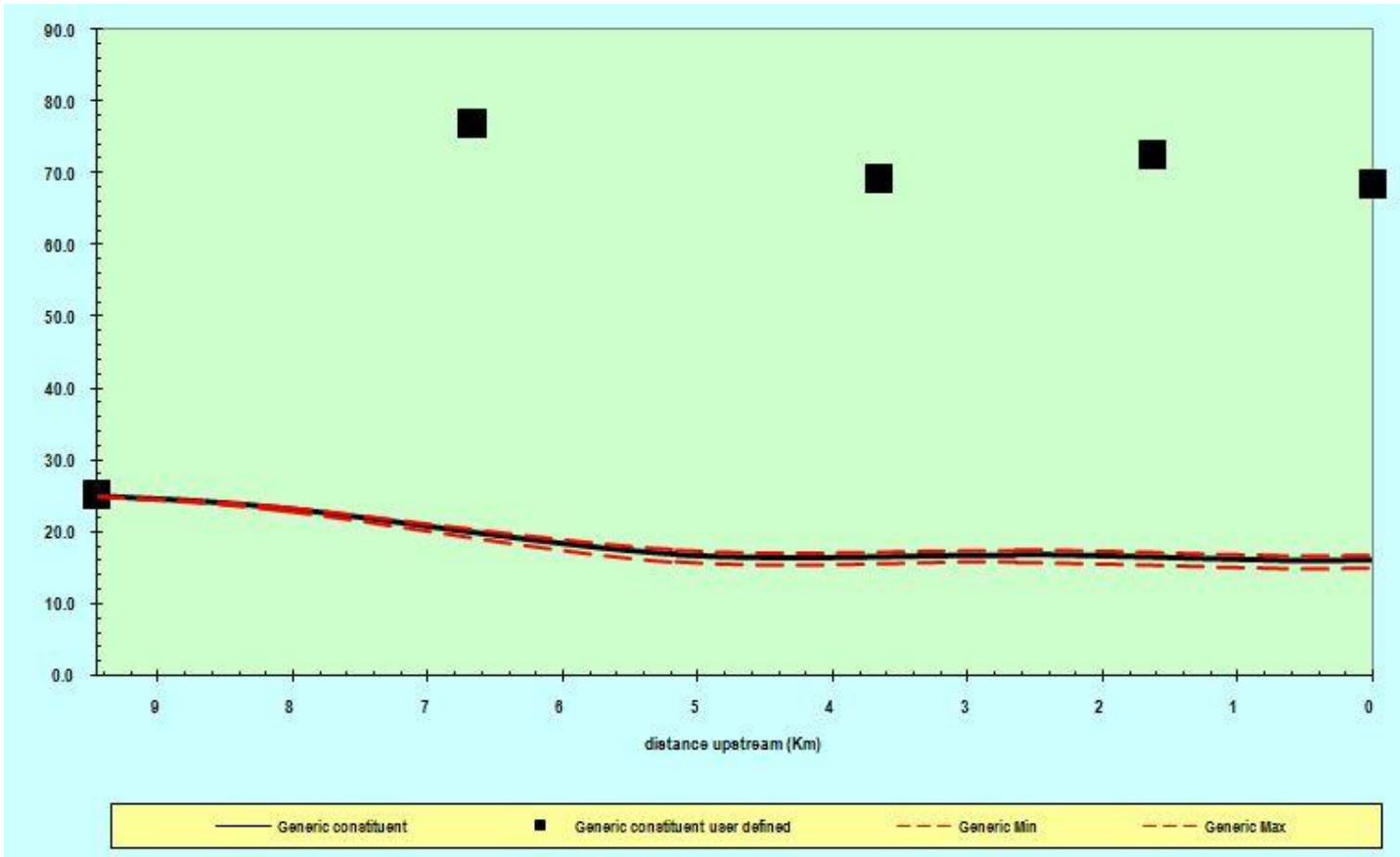

Gambar 9. Hasil model skenario dua parameter COD

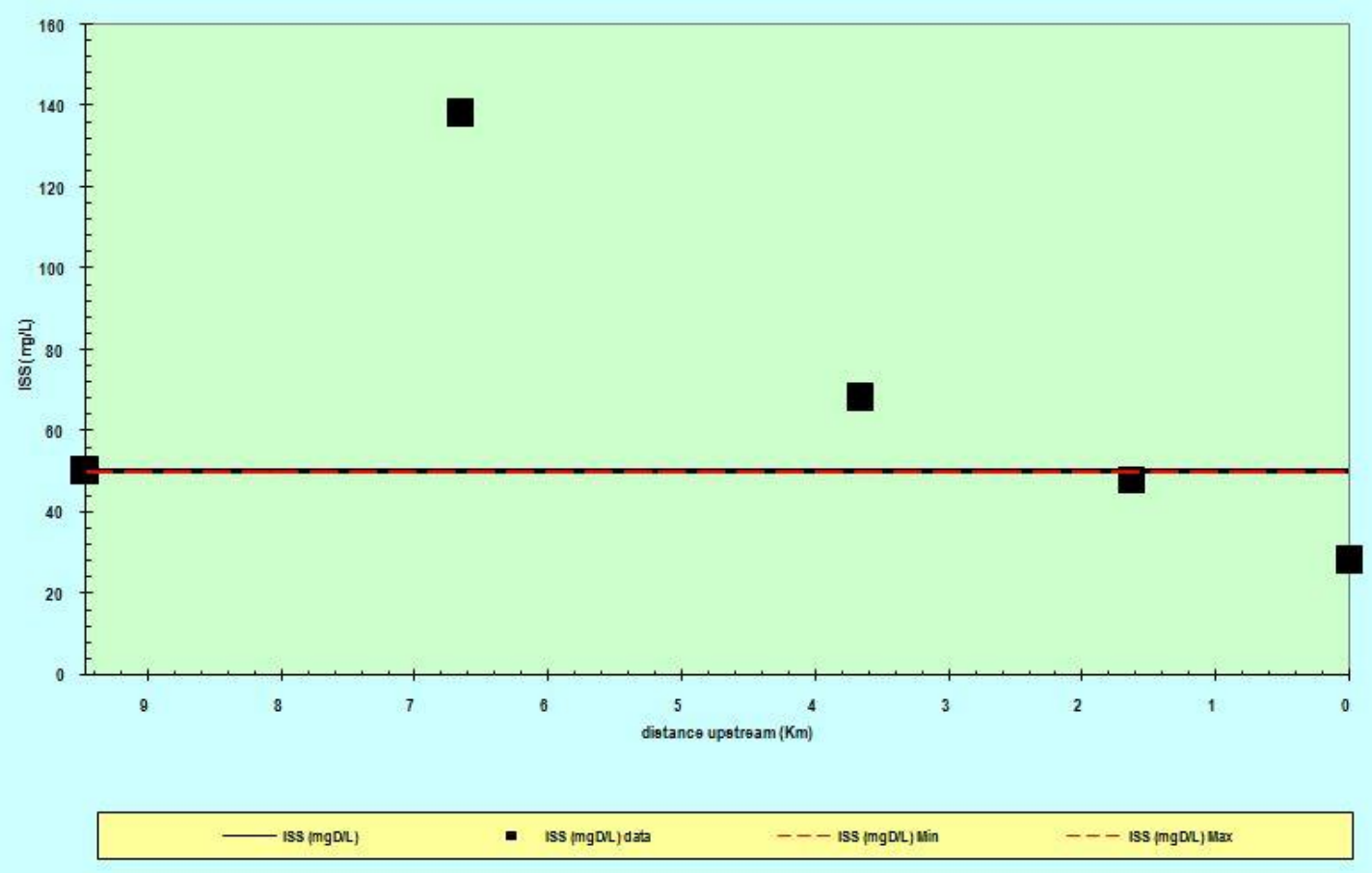

Gambar 10. Hasil model skenario dua parameter TSS

Simulasi model tiga merupakan simulasi yang memberikan gambaran kondisi pada hulu sungai dan badan sungai yang memenuhi baku mutu air kelas II sesuai Peraturan Gubernur DIY no. 20 
tahun 2008 tentang Baku Mutu Air di DIY, dengan sumber pencemar yang di trial and error sampai model mendekati baku mutu kelas II. Hasil dari simulasi model skenario tiga dapat dilihat pada Gambar 11, 12 dan 13 untuk parameter BOD, COD dan TSS secara berurutan.

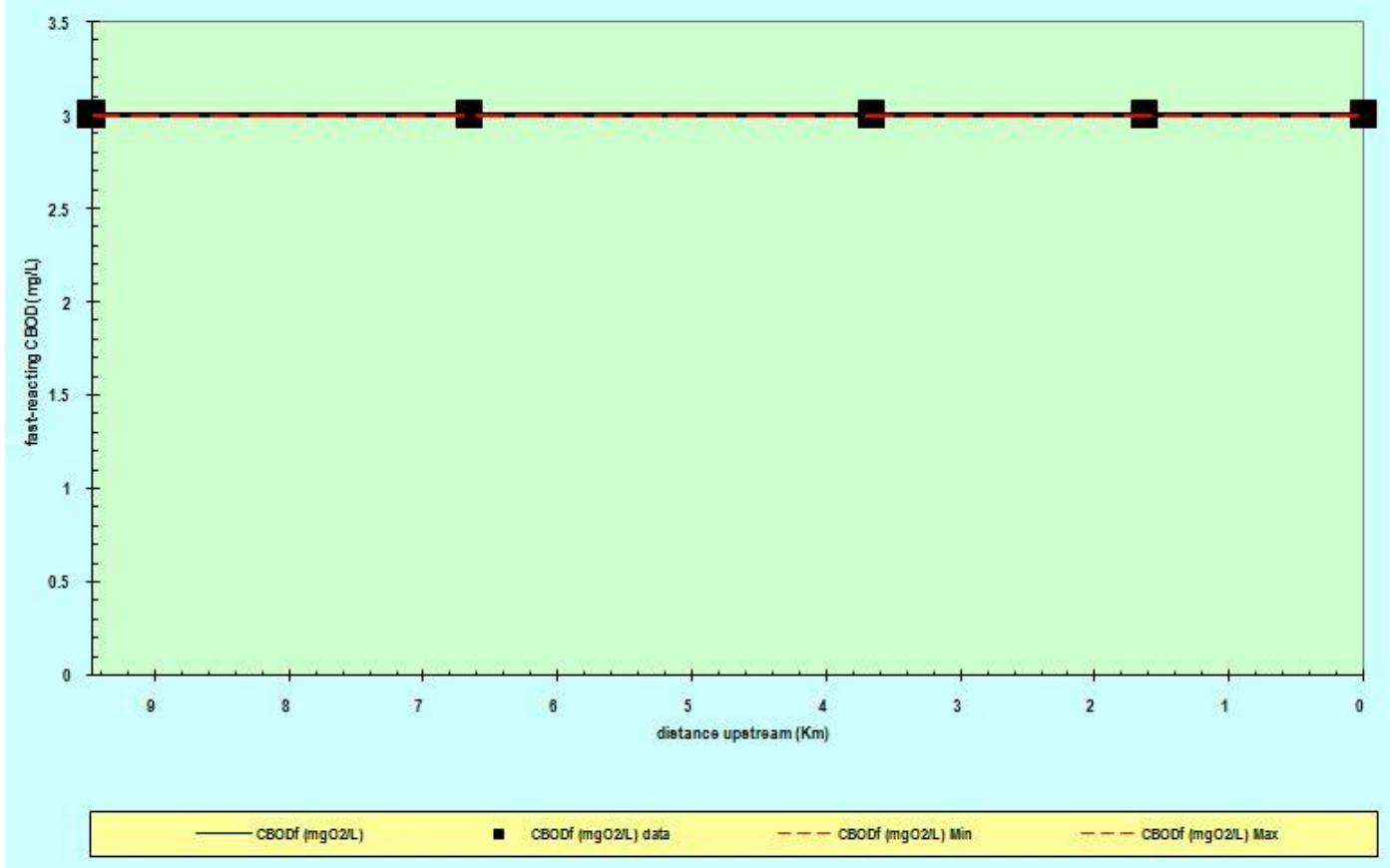

Gambar 11. Hasil model skenario tiga parameter BOD

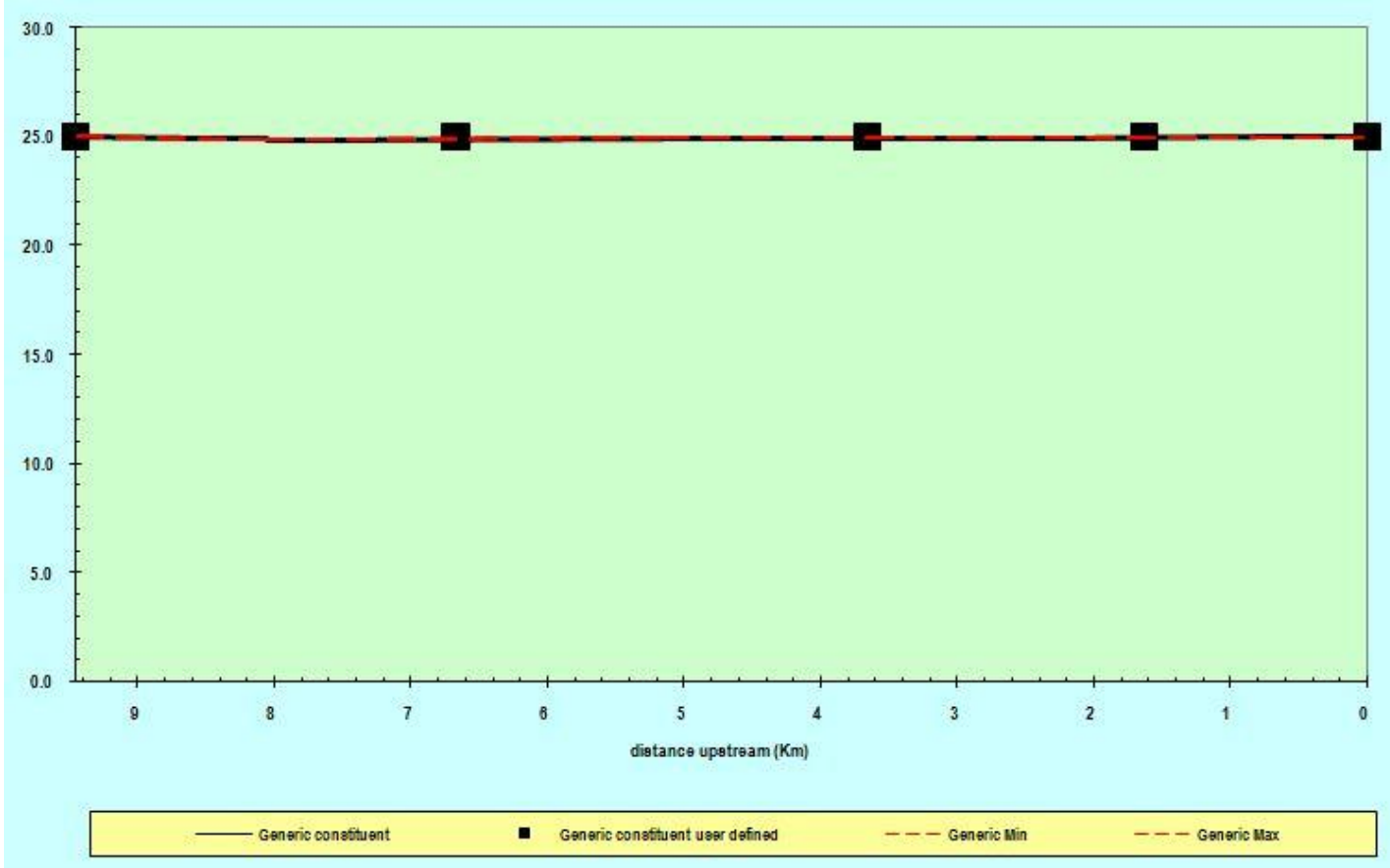

Gambar 12. Hasil model skenario tiga parameter BOD 


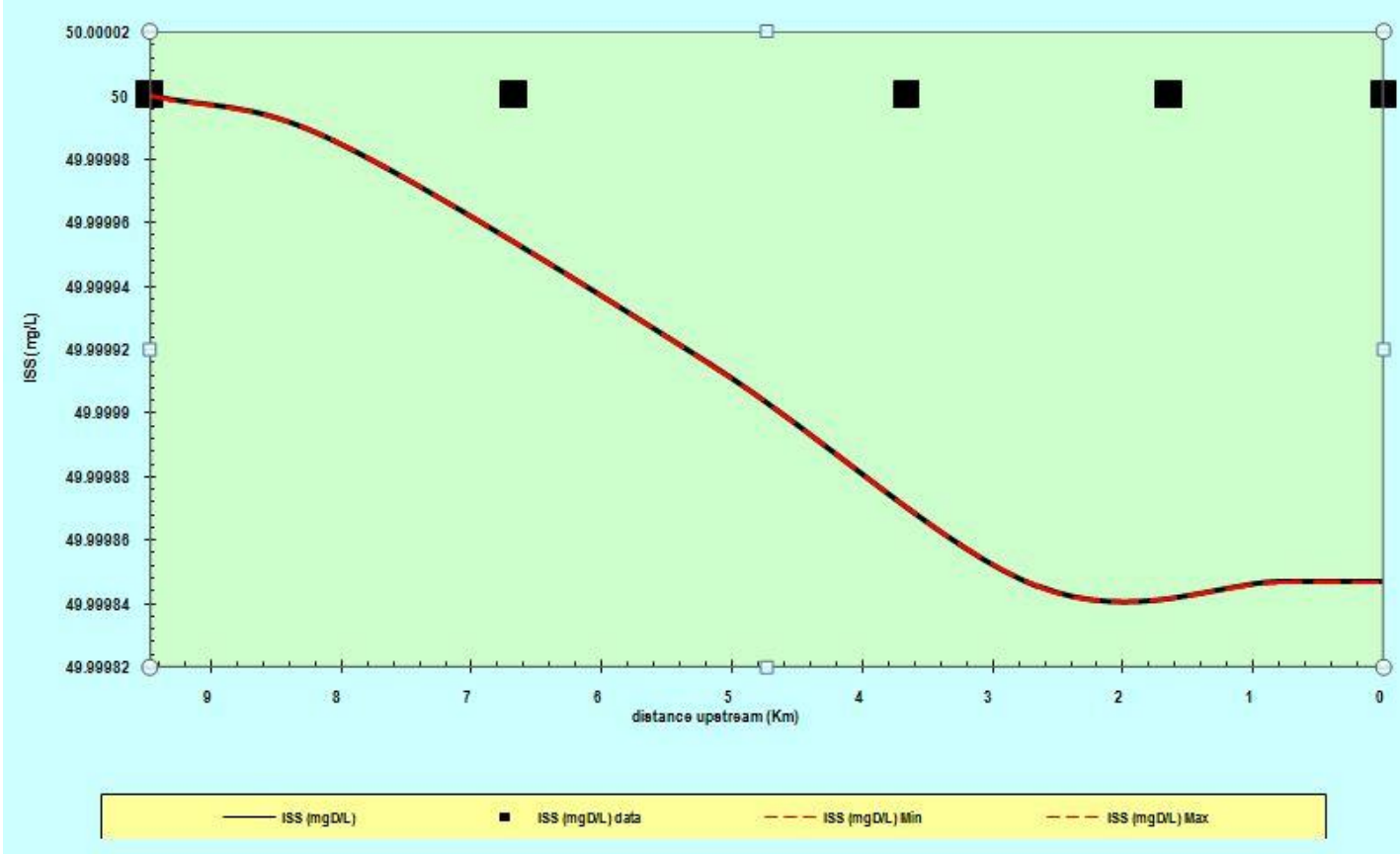

Gambar 13. Hasil model skenario tiga parameter BOD

\subsection{Perhitungan daya tampung beban pencemar}

Perhitungan daya tampung beban pencemar dilakukan dengan membandingkan skenario tiga dengan skenario dua. Dari kedua simulasi tersebut, didapatkan hasil berupa debit dan besarnya konsentrasi di tiap segmen pada lembar kerja source summary. Data beban pencemar skenario dua dan skenario tiga dapat dilihat pada Tabel 2 dan Tabel 3. Berdasarkan beban pencemar yang didapat, maka langkah selanjutnya adalah melakukan perhitungan daya tampung beban pencemar. Hasil perhitungan daya tampung beban pencemar dapat dilihat pada Tabel 4.

Berdasarkan perhitungan daya tampung yang diperoleh dari selisih konsentrasi beban pencemar maksimum dengan konsentrasi beban tanpa pencemar dapat dilihat secara garis besar bahwa daya tampung untuk parameter BOD, COD, dan TSS masih bernilai positif (+), yang menyatakan bahwa nilai daya tampung beban pencemar yang dapat diterima oleh Sungai Widuri. Penelitian ini menunjukkan bahwa sungai Widuri masih mampu menampung beban pencemar. Menurut Hendrasarie dan Cahyarani (2008) alam sebenarnya memiliki kemampuan mengatasi masalah pencemaran yang terjadi, mekanisme ini disebut self purification. Self Purification adalah pemurnian diri; upaya pemurnian air dari zat pencemar yang terkandung di dalamnya oleh proses alamiah dengan bantuan proses reaerasi yang mempercepat proses pencampuran oksigen dalam 
air. Menurut Brontowiyono et al (2010) pengelolaan sungai bisa dilakukan dengan melibatkan berbagai pihak terkait baik yang berasal dari pemerintahan, pihak swasta, perguruan tinggi, Lembaga Swadaya Masyarakat (LSM) serta pihak terkait lainnya

Tabel 2. Beban pencemar skenario dua

\begin{tabular}{cccc}
\hline Segmen & $\begin{array}{c}\text { TSS } \\
(\mathrm{Kg} / \mathrm{hari})\end{array}$ & $\begin{array}{c}\text { BOD } \\
(\mathrm{Kg} / \mathrm{hari})\end{array}$ & $\begin{array}{c}\text { COD } \\
(\mathrm{Kg} / \mathrm{h} \text { ari })\end{array}$ \\
\hline 1 & 0,10368 & 0,006221 & 0,05184 \\
\hline 2 & 0,17280 & 0,010368 & 0,08640 \\
\hline 3 & 0 & 0 & 0 \\
\hline 4 & 0,01296 & 0,000778 & 0,00648 \\
\hline
\end{tabular}

Tabel 3. Beban pencemar skenario tiga

\begin{tabular}{cccc}
\hline Segmen & $\begin{array}{c}\text { TSS } \\
(\text { Kg/hari })\end{array}$ & $\begin{array}{c}\text { BOD } \\
(\text { Kg/hari })\end{array}$ & $\begin{array}{c}\text { COD } \\
(\text { Kg/hari })\end{array}$ \\
\hline 1 & 43632 & 2617,92 & 21816 \\
\hline 2 & 2548,8 & 152,928 & 1273,3 \\
\hline 3 & 0,63504 & 0,03810 & 0,31752 \\
\hline 4 & 3326,4 & 100,584 & 1663,2 \\
\hline
\end{tabular}

Tabel 4. Hasil perhitungan daya tampung beban pencemar

\begin{tabular}{cccc}
\hline Segmen & $\begin{array}{c}\text { TSS } \\
(\text { Kg/hari })\end{array}$ & $\begin{array}{c}\text { BOD } \\
(\text { Kg/hari })\end{array}$ & $\begin{array}{c}\text { COD } \\
(\text { Kg/hari })\end{array}$ \\
\hline 1 & 43631,896 & 2617,919 & 21816,948 \\
\hline 2 & 2548,627 & 152,920 & 1274,314 \\
\hline 3 & 0,635 & 0,040 & 0,318 \\
\hline 4 & 3326,387 & 199,579 & 1663,194 \\
\hline
\end{tabular}

\section{KESIMPULAN}

Kualitas air Sungai Widuri untuk parameter BOD dan COD masih melebihi baku mutu air kelas II berdasarkan Peraturan Gubernur DIY no. 20 tahun 2008 tentang Baku Mutu Air di DIY. Nilai daya tampung parameter BOD pada segmen satu yaitu sebesar 2671,919 kg/hari, segmen dua sebesar 152,920 kg/hari, segmen tiga sebesar 0,040 kg/hari, segmen empat sebesar 199,579 $\mathrm{kg} / \mathrm{hari}$. Nilai daya tampung parameter COD pada segmen satu sebesar 21815,948 kg/hari, segmen dua sebesar 1274,314 kg/hari, segmen tiga sebesar 0,318 kg/hari, segmen empat sebesar 1663,194 $\mathrm{kg} / \mathrm{hari}$. Nilai daya tampung parameter TSS pada segmen satu yaitu sebesar 43631,896 kg/hari, segmen dua sebesar 2548,627 kg/hari, segmen tiga sebesar 0,635 kg/hari, segmen empat sebesar 
$3326,387 \mathrm{~kg} / \mathrm{hari}$. Secara garis besar nilai daya tampung pada semua parameter dan setiap segmen masih bernilai positif (+) yang menyatakan nilai daya tampung beban pencemar yang dapat diterima oleh Sungai Widuri.

\section{DAFTAR PUSTAKA}

Brontowiyono,W., Kasam., Ribut, L., dan Agustina, I. (2013). Strategi Penurunan Pencemaran Limbah Domestik Sungai Code DIY. Jurnal Jurnal Sains dan Teknologi Lingkungan, 5 (1): $36-47$.

Deksissa, T. (2004). Dynamic Integrated Modeling of Basic Water Quality and Fate and Effect of Organic contaminants in rivers. Thesis, Ghent University Belgium.

Effendi, H. (2003). Telaah Kualitas Air. Yogyakarta: Penerbit Kanisius.

Hendrasarie, N dan Cahyarani. (2008). Kemampuan Self Purification Kali Surabaya, ditinjau dari Parameter Organik Berdasarkan Model Matematis Kualitas Air. Jurnal Ilmiah Teknik Lingkungan, 2 (1): 1-11.

Irsanda, P. G. R. (2014). Analisis Daya Tampung Beban Pencemaran Kali Pelayaran, Kabupaten Sidoarjo Dengan Metode QUAL2KW. Jurnal Teknik POMITS, 3 (1): 47-52.

Marlina, N. (2015). Evaluasi Daya Tampung Terhadap Beban Pencemar Menggunakan Model Kualitas Air (Studi Kasus: Sungai Winongo). Jurnal Inovasi dan Kewirausahaan, 4(2): 78-86.

Mahyudin, S dan Prayoho, T.B. (2015). Analisis Kualitas Air dan Strategi Pengendalian Pencemaran Sungai Metro di Kota Kepajen Kabupaten Malang. Jurnal Pembangunan dan Alam Lestari, 6 (2): 105-114.

Peraturan Gubernur DIY No. 20 tahun 2008 tentang Baku Mutu Air di Daerah Istimewa Yogyakarta.

Peraturan Menteri Negara Lingkungan Hidup Nomor 1 tahun 2010 tentang Tata Laksana Pengendalian Pencemaran Air.

Prihartanto dan Budiman, E.B. (2007). Sistem Informasi Pemantauan Dinamika Sungai Siak .Alami, 12 (1): 52-60.

Rusnugroho, A., dan Masduqi, A. (2012). Aplikasi QUAL2Kw sebagai Alat Bantu Perhitungan Daya Tampung Beban Pencemaran Kali Madiun (Segmen Kota Madiun). Scientific Conference of Environmental Technology IX-2012, Advances in Agricultural and Municipal Waste Technology to Anticipate Food and Energy Crisis. 
Wardhana,W.A. (2004). Dampak Pencemaran Lingkungan. Yogyakarta: Penerbit Andi.

Yuliastuti, E. (2011). Kajian Kualitas Air Sungai Ngringo Karanganyar dalam Upaya Pengendalian Pencemaran Air. Tesis, Universitas Diponegoro.

Yogafanny, E. (2015). Pengaruh Aktifitas Warga di Sempadan Sungai terhadap Kualitas Air Sungai Winongo. Jurnal Sains dan Teknologi Lingkungan, 7 (1): 41-50. 